\title{
ASPECTOS LEGAIS DA EDUCAÇÃO INFANTIL NO BRASIL E AS POLÍTICAS DE FINANCIAMENTO
}

\author{
Paulo Rogério de Souza ${ }^{1}$, João Paulo Pereira Coelho ${ }^{2}$ \\ ${ }^{1}$ Doutor em Educação pela Universidade Estadual de Maringá - UEM e Doutor em Estudos Clássicos pela Universidade \\ de Coimbra (Portugal). Docente colaborador do Departamento de Teoria e Prática da Educação (DTP), da Universidade \\ Estadual de Maringá - UEM, Maringá, PR. E-mail: paulolucka@gmail.com \\ ${ }^{2}$ Doutor em Educação na área de História e Historiografia da Educação pela Universidade Estadual de Maringá - UEM. \\ Docente da Universidade Estadual de Maringá - UEM, Maringá, PR.
}

\section{RESUMO}

Esta pesquisa apresenta os aspectos legais que instituíram a educação infantil como etapa da educação básica, a partir da Constituição Federal de 1988 e da LDB 9.394/96, mostrando os avanços que a legislação trouxera para o atendimento da criança, no ambiente escolar. Assim, este trabalho, vinculado ao Grupo de Estudos e Pesquisa em Políticas Educacionais, Gestão e Financiamento da Educação (GEPEFI), tem como preocupação fazer uma análise crítica da criação dos fundos contábeis, FUNDEF e FUNBEB, a partir da década de 1990, apontado seus pontos positivos e negativos para o atendimento da educação básica, destacando a importância desses fundos para a manutenção técnica e financeira da educação infantil. Por fim, é importante destacar as melhorias que as políticas de financiamento propiciaram à educação infantil, principalmente com a criação do FUNDEB, em 2006, e quais as consequências que poderão acarretar a essa etapa da educação, com seu término legal em 2020.

Palavras-chave: Educação infantil. Aspectos legais. Financiamento educacional. FUNDEB. PEC no 15/2015.

\section{LEGAL ASPECTS OF CHILDREN EDUCATION IN BRAZIL AND FINANCING POLICIES}

\section{ABSTRACT}

This research presents the legal aspects that instituted childhood education as a stage of basic education, starting with the Federal Constitution of 1988 and LDB 9.394 / 96, showing the advances that legislation had brought to the care of the child in the school environment. Thus, this work, linked to the Group of Studies and Research in Educational Policies, Management and Financing of Education (GEPEFI), has as a concern to make a critical analysis of the creation of accounting funds, FUNDEF and FUNBEB, from the positive and negative points for the basic education, highlighting the importance of these funds for the technical and financial maintenance of early childhood education. Finally, it is important to highlight the improvements that the funding policies have given to early childhood education, especially with the creation of FUNDEB, in 2006, and what the consequences may be for this stage of education, with its legal termination in 2020.

Keywords: Childhood education. Legal aspects. Educational funding. FUNDEB; PEC No. 15/2015.

\section{INTRODUÇÃO}

Desde a antiguidade até a modernidade, o cuidado e a educação da criança, nos primeiros anos de vida, esteve geralmente sob a responsabilidade da família, principalmente da mulher, na figura da mãe.

Após a Revolução Industrial, no século $\mathrm{XVIII,} \mathrm{e,} \mathrm{principalmente,} \mathrm{na} \mathrm{sua} \mathrm{potencialização,}$ no século XIX, ocorreram diversas mudanças na estrutura da sociedade que contribuíram para que houvessem uma nova forma de atendimento à criança.

Com a industrialização da sociedade e a processo de urbanização que esta impulsionou, a mulher foi forçada a entrar no mercado de trabalho por necessidades econômicas, deixando de dispensar integralmente o seu tempo ao cuidado doméstico e à educação da criança, no interior da casa.

Para suprir a lacuna deixada pela família contemporânea, foram criadas instituições 
chamadas creches para atender as crianças, sendo adotadas inicialmente com caráter assistencial. Ou seja, o papel da creche era ser um lugar de cuidado dos filhos das trabalhadoras, servindo como suporte familiar de assistência às mulheres que assumiram lugar no mercado de trabalho.

A partir da secunda metade do século XX, passou-se a ter uma preocupação social maior para com o cuidado da criança, destacando a importância do atendimento infantil para o desenvolvimento adequado desta fase da vida, antes mesmo da criança ter idade para uma educação elementar.

Esta preocupação pode ser destacada pela atenção dada à infância ${ }^{1}$ pelos organismos e organizações internacionais que, a partir da década de 1950, passaram a realizar congressos mundiais, onde elaboraram documentos em defesa e incentivo ao desenvolvimento da crianças. Dentre esses documentos, citam-se a Declaração Universal dos Direitos da Criança, datado de 1959, e a Convenção Mundial dos Direitos da Criança, de 1989, que influenciaram a progressiva ampliação do atendimento a criança nos primeiros anos de vida.

Princípio 4: A criança gozará os benefícios da previdência social. Terá direito a crescer e criarse com saúde; para isto, tanto à criança como à mãe, serão proporcionados

cuidados e proteções especiais, inclusive adequados cuidados pré e pós-natais. A criança terá direito a alimentação, recreação e assistência médica adequadas (ONU, 1959).

No Brasil, as políticas de atendimento assistencial da criança seguiram, a passos lentos, as tendências mundiais, influenciadas pelos organismos e organizações internacionais, como a UNESCO e a UNICEF, até a década de 1980.

\footnotetext{
1 “Infância tem um significado genérico e, como qualquer outra fase da vida, esse significado é função das transformações sociais: toda sociedade tem seus sistemas de classes de idade e a cada uma delas é associado um sistema de status e papel" (KHULMANN, 1998, p. 16).
}

A partir da segunda metade da década de 1980, começou uma ampla movimentação e discussão - civil e governamental - sobre o tema educação da criança, o que gerou a necessidade de se reconhecer a educação infantil como uma modalidade de ensino da educação básica através de instrumentos legais.

Assim, o objetivo desse trabalho foi mostrar os avanços que aspectos legais trouxeram à Educação Infantil, sustentados pela Constituição Federal de 1988, o ECA de 1990 e a LDB de 1996. Também buscou-se destacar a importância dos fundos contábeis de financiamento educacional para o atendimento desta etapa da Educação Básica, a partir da segunda metade da década de 1990 . Para isso, a metodologia adotada nesta discussão partiu de uma análise bibliográfica, de caráter teórico, tendo como referencial o Materialismo Histórico.

\section{Os aspectos legais como avanços no reconhecimento da educação infantil}

Os aspectos legais como avanço para o reconhecimento da educação infantil no Brasil se deu incialmente com o texto original da Constituição Federal de 1988, onde a Carta Magna trazia 0 atendimento de crianças de 0 (zero) a 6 (seis) anos de idade como dever e obrigação do Estado, no seu Art. 208, inciso IV.

Como o objetivo de reforçar o que foi expresso no Constituição Federal de 1988, o Estatuto da Criança e do Adolescente (ECA) de 1990 reitera nos Art. 53 e Art. 54 esse direito ao atendimento educacional às crianças de 0 (zero) a 6 (seis) anos, que precisava ser oferecido e mantido pelo Estado de maneira obrigatória. (BRASIL, 1990)

No entanto, o termo Educação Infantil somente apareceu em um regimento legal brasileiro com a Lei no 9.394, de 20 de dezembro de 1996, no Art. 9o, do texto original. Foi também com a Lei de Diretrizes e Bases da Educação Nacional de 1996, que a Educação Infantil passou a fazer parte da Educação Básica: "Art. 21. A educação escolar compõe-se de:I - educação básica, formada pela educação infantil, ensino fundamental e ensino médio; II - educação superior" (BRASIL, 1996). Desta maneira, a educação infantil tornando-se uma das etapas deste nível de educação, como redigido no Art. 29: "A educação infantil, primeira etapa da educação básica, tem como finalidade o desenvolvimento integral da criança até seis anos de idade, em seus aspectos físico, psicológico, 
intelectual e social, complementando a ação da família e da comunidade" (BRASIL, 1996).

Este Art. 29, da LDB de 1996, foi alterado pela redação dada pela Lei no 12.796 , de 2013, que redefiniu a duração do ensino fundamental de 8 (oito) para 9 (nove) anos, tornando obrigatória a matrícula escolar nesta etapa, a partir 6 (seis) aos de idade. Assim, a educação infantil, entendida como a primeira fase da educação básica, passou a ser definida como faixa etária dos 0 (zero) aos 5 (cinco) anos de idade:

Art. 29. A educação infantil, primeira etapa da educação básica, tem como finalidade 0 desenvolvimento integral da criança de até 5 (cinco) anos, em seus aspectos físico, psicológico, intelectual e social, complementando a ação da família e da comunidade. (Redação dada pela Lei ํo 12.796, de 2013) (BRASIL, 1996)

A Lei no 12.796, de 2013 também alterou o texto original da LDB no 9.394/96, no Art. 30, definindo a oferta da educação infantil em duas etapas: "I - creches, ou entidades equivalentes, para crianças de até 3 (três) anos de idade; e II pré-escolas, para as crianças de 4 (quatro) a 5 (cinco) anos de idade" (BRASIL, 2013).

Ao incluir a faixa etária dos 0 (zero) aos 3 (três) anos na educação infantil, a LDB de 1996 promoveu uma grande mudança no atendimento da criança, pois, como apresenta Gaspar (2010, p. 123):

[...] a faixa etária de zero a três anos sempre esteve mais afeta a espaços de amparo e promoção social, com um atributo mais assistencial e de guarda das crianças, com cuidados físicos, de saúde e de alimentação. Assim, grande parte da demanda era atendida por instituições filantrópicas e associações comunitárias.

Apesar da diferenciação legal dessas duas etapas, Gaspar (2010, p. 121) ressalta ainda que: “[...] a diferença entre creches e pré-escolas é feita unicamente pelo critério de faixa etária, sendo ambas as instituições de educação infantil, com o mesmo objetivo - desenvolvimento da criança, em seus múltiplos aspectos".

Dentro dos aspectos legais também passou a ser definida a responsabilidade de oferta da educação infantil que deveria ser mantida prioritariamente, segundo a Constituição Federal de 1998, pelos municípios. No entanto, para manter a educação infantil, os municípios precisariam receber a colaboração dos diferentes entes de governo: "Art. 30. Compete aos municípios, VI - manter, com a cooperação técnica e financeira da União e do Estado, programas de educação infantil e de ensino fundamental; (Inciso com redação dada pela Emenda Constitucional no 53, de 2006)" (BRASIL, 1988).

Desta forma, pode-se verificar que, os munícipios assumiram a obrigatoriedade de exercer a responsabilidade de manutenção e organização do sistema de educação infantil. Mas esta responsabilidade teria que ser exercida em regime de colaboração com os estados e com o governo federal, que deveriam subsidiar técnica e financeiramente a sua oferta, como regulamentado no Art. 8ㅇ, da LDB 9.394/96 “A União, os Estados, o Distrito Federal e os Municípios organizarão, em regime de colaboração, os respectivos sistemas de ensino". Esta colaboração estava reforçadas nos artigos seguintes, nos quais estão especificadas as responsabilidades para com a educação de cada ente federado: União (Art.9), estados (Art. 10) e Municípios (Art. 11). (BRASIL, 1996).

Essa cooperação técnica e financeira dos estados e da União para com os municípios, teve como premissa o papel de auxiliar os entes federados com menor capacidade de arrecadação financeira (municípios) a manter sua responsabilidade legal na manutenção desta etapa da educação.

\section{O financiamento da educação infantil no Brasil pós-1990}

Como se pode verificar no Art. 30 da Carta Magna de 1988, a manutenção da educação infantil deve ser ofertada em regime de cooperação técnica e financeira entre a União, os estados e municípios. Atualmente, essa cooperação ocorre através de fundos de financiamento da educação. (BRASIL, 1988) 
Mas esta cooperação, até a década de 1990, ocorria através da realização de convênios ${ }^{2}$ entre os entes federados, numa escala hierárquica de poder: dos municípios para com os estados, ou destes (municípios e Estados) para com o governo federal.

Segundo Paulo Sena, estes convênios para financiamento e manutenção da educação básica, em especial a educação infantil, seguiam critérios subjetivos e, ainda de acordo com o autor, estavam sujeitos às influências políticas: "A União, ao repassar os recursos e eventualmente prestar assistência técnica, estabelece condições, cuja verificação é mais suscetível a injunções político-partidárias" (SENA, 2015, p. 3).

As discussões sobre a necessidade da criação de fundos de financiamento da educação básica acorreram com maior ênfase no Brasil a partir da década de 1990, sob influência das políticas neoliberais, partindo inicialmente do governo do presidente Fernando Collor de Mello (1990-1992) e reforçadas pelo Governo do presidente Fernando Henrique Cardoso (19952002).

Seguindo orientações de agências internacionais do sistema ONU, através de acordos multilaterais, os países em desenvolvimento, signatários desses acordos, deveriam privilegiar a educação fundamental em detrimento às outras etapas da educação, como apresentado na Declaração Mundial sobre Educação para Todos: satisfação das necessidades básicas de aprendizagem, de 1990.

A UNESCO e a UNICEF, juntamente com o Banco Mundial e outros organismos e organizações intergovernamentais, conduziram as discussões nesta conferência internacional realizada no ano de 1990, em Jomtien, na Tailandia, procurando estabelecer compromissos e convencer todos os países participantes dentre eles o Brasil - que o principal objetivo da educação básica deveria ser garantir a todas as pessoas os conhecimentos básicos necessários a uma vida digna, condição insubstituível para o advento de uma sociedade mais humana e mais justa (DECLARAÇÃO DE JOMTIEN, 2001). Por isso, os investimentos na educação básica, (ensino fundamental) deveria ser privilegiada por todos os países signatários dessa declaração. Os outros níveis de educação deveriam ser terceirizados ou

\footnotetext{
2 “[...] convênios - instrumentos que se ajustam a políticas definidas pela instância federativa de maior abrangência (União em relação a estados e municípios e estados em relação a municípios)" (SENA, 2015, p. 3)
}

delegados na totalidade de sua manutenção à iniciativa privada.

De acordo com o documento extraído da Conferência de Jomtien, em seu Art. 5, a educação fundamental precisava ser universalizada em busca de satisfazer as necessidades básicas das crianças: "O principal sistema de promoção da educação básica fora da esfera familiar é a escola fundamental. A educação fundamental deve ser universal, garantir a satisfação das necessidades básicas de aprendizagem de todas as crianças [...]" (UNESCO, 1990).

No entanto, ainda que o discurso neoliberal propagado pelos organismos e organizações internacionais, de privilegiar a educação básica na etapa do ensino fundamental, fosse em defesa de uma educação que proporcionasse uma vida digna, condição insubstituível para o advento de uma sociedade mais humana e mais justa, o que se verificou na prática foi que seu objetivo era outro: a busca por uma sistema de ensino elementar, que deveria formar minimamente o trabalhador, como mão de obra para o mercado de trabalho, como pode ser visto nas orientações do Banco Mundial:

A estratégia do Banco Mundial para a redução da pobreza se concentra em promover o uso produtivo do trabalho, que é a principal atividade dos pobres, e a prestação de serviços sociais básicos aos mais necessitados. 0 investimentos em educação contribuem para a acumulação de capital humano que é essencial para atingir rendimentos mais elevados e crescimento econômico sustentado. Educação, especialmente a educação básica (primária e secundária do primeiro ciclo), ajuda a reduzir a pobreza através do aumento da produtividade dos pobres, reduzindo a natalidade e melhorando a saúde, e fornecendo às pessoas as habilidades que necessitam para participar plenamente na economia 
e sociedade (BANCO MUNDIAL, 1995, p. 1).

Para isso, o Banco mundial reforçava em seus documentos a necessidade de investimento na educação básica (ensino fundamental): "A educação básica deve ser a primeira prioridade para os gastos públicos educação em países que ainda não alcançaram perto de matrícula universal no ciclo básico primário e secundário" (BANCO MUNDIAL, 1995 p. 4).

Partindo deste ponto de vista, pode-se dizer que foi para atender às orientações dos organismos e organizações internacionais que o Fundo de Manutenção e Desenvolvimento do Ensino Fundamental e de Valorização do Magistério (FUNDEF) acabou sendo criado em meados da década de 1990, no governo do então presidente Fernando Henrique Cardoso. Isso porque o FUNDEF tinha como objetivo principal atender apenas a educação fundamental, excluindo a educação infantil, o ensino médio e o nível superior, bem como diversas modalidades de ensino como, por exemplo, a educação de jovens e adultos.

\section{FUNDEF e FUNDEB: os fundos contábeis de} financiamento educacional

O Fundo de Manutenção e Desenvolvimento do Ensino Fundamental e de Valorização do Magistério (FUNDEF) foi criado em 1997, em meio às políticas neoliberais do governo FHC, impulsionadas pelo Plano Diretor da Reforma e Aparelho do Estado. O Plano de Reforma do estado brasileiro foi conduzido pelo ministro Bresser Pereira, do Ministério da Administração e Reforma do Estado (MARE), em busca de um estado-mínimo. Estas reformas refletiram também na educação, como pode ser visto no financiamento educacional, com a criação do FUNDEF.

Esse fundo de natureza contábil para financiamento educacional tinha como princípio, segundo Davies (2006, p. 765): “[...] disponibilizar um valor anual mínimo nacional por matrícula no ensino fundamental de cada rede municipal e estadual, de modo a possibilitar o que o governo federal alegou ser suficiente para um padrão mínimo de qualidade [...]".

Assim, o FUNDEF foi criado para substituir as formas anteriores de financiamento educacional no Brasil, que eram realizadas através de convênios e que, segundo Sena (2015), ofereciam assistência técnica e financeira para a educação, estabelecendo condições, cuja verificações eram mais suscetíveis às injunções político-partidárias. Essas injunções eram negativas, já que a liberação de recursos dependia muito das relações político-partidárias entre as diferentes entidades federativas, sendo muitas vezes favorecidos aqueles estados e/ou municípios que tivessem uma relação política mais próxima com o ente federado com maior capacidade de arrecadação de recursos financeiros, no caso a União em relação aos estados e municípios. Os municípios sempre foram dependentes dos recursos dos seus estados e da também do governo federal.

Após a sua aprovação, o FUNDEF trouxera certos avanços para a etapa da educação fundamental. Entre esses avanços estavam: obrigatoriedade de repasses de recursos da União para a educação fundamental; critérios definidos para a manutenção de um fluxo contínuo de recursos; regras claras para efetivar a colaboração técnica e financeira entre os estados e os municípios.

No entanto, o FUNDEF também apresentou algumas deficiências. A primeira delas é que o fundo foi criado para durar apenas 10 anos, tendo data para iniciar e para acabar. Também deixou de contemplar outras etapas da educação básica como, por exemplo, o ensino médio e a educação infantil, que não foram atendidas pelo fundo. Outra deficiência foi a participação financeira quase inexistente da União na manutenção do fundo, ainda que o governo federal apresentasse um orçamento e uma capacidade de arrecadação muito maior que os estados e os municípios.

Isso pode ser entendido como uma intenção do governo central vigente em cumprir apenas as orientações dos organismos e organizações internacionais, na busca de uma formação mínima do trabalhador, preparando-o para o mercado de trabalho e não efetivamente uma preocupação estatal em promover um sistema de ensino público de qualidade, com uma educação continuada para todos e em todos os níveis, etapas e modalidades.

O FUNDEF, iniciado em 1997, perdurou no financiamento da educação fundamental até o ano de 2006, sendo posteriormente substituído por um outro fundo contábil, o Fundo de Manutenção e Desenvolvimento da Educação Básica e de Valorização dos Profissionais da Educação (FUNDEB). 
O FUNDEB foi criado no governo do presidente Luiz Inácio Lula da Silva (2003-2010) e entrou em vigor no ano de 2007. Ele substituiu e reformulou o que fundo anterior promovia, ampliando seu atendimento no sistema de ensino público, passando a contemplar toda a educação básica, inclusive o ensino médio e a educação infantil, antes excluídos do fundo de financiamento educacional.

Comparando o antigo FUNDEF com o atual FUNDEB, Sena (2015) destaca que houveram algumas mudanças que trouxeram avanços significativos para a educação básica. Entre estas mudanças citadas pelo autor estão: a estipulação do investimento da União em no mínimo $10 \%$ do valor do fundo; o estabelecimento de prazo para a criação do piso salarial para o magistério através de lei $i^{3}$; a criação de um espaço federativo de negociação, através da Comissão Intergovernamental de Financiamento para a Educação Básica, na qual fazem parte representantes das esferas municipal, estadual e da União (SENA, 2015).

Outra novidade significativa que 0 FUNDEB promoveu foi a inclusão do financiamento para a educação infantil através de um fundo contábil, já que esta modalidade não era contemplada pelo antigo FUNDEF.

Gaspar destaca ainda que, apesar da disponibilização legal de repasse de recursos financeiros do novo fundo para a educação infantil mereçam maior destaque, outros pontos também devem ser salientados:

[...] o FUNDEB traz outras características

fundamentais para a Educação Infantil. Destacam-se em relação a isso, a garantia da integralidade e a integridade da Educação Infantil, desde o nascimento, ao incluir a creche. Por muito tempo se argumentou sobre a importância do financiamento para dar à creche a relevância social, educacional e política como instituição que garanta $o$ direito da

\footnotetext{
${ }^{3}$ A Lei $n^{\circ} 11.738$, de 16 de junho de 2008 , instituiu o piso salarial profissional nacional para os profissionais do magistério público da educação básica, regulamentando a disposição constitucional (alínea 'e' do inciso III do caput do artigo 60 do Ato das Disposições Constitucionais Transitórias).
}

criança de até três anos à educação, destituindo-a do status de assistência. Se a creche tivesse sido excluída do fundo, grande seria o risco de retrocesso na finalidade pedagógica (GASPAR, 2010, p. 129).

Ao garantir o financiamento da educação infantil, o FUNDEB buscou corrigir uma injustiça que esta modalidade sofrera na sua falta de auxílio e assistência financeira e técnica por parte da União e dos estados, já que os municípios eram os responsáveis legais da sua manutenção até a sua inclusão no fundo.

Os recursos do FUNDEB, a partir de 2007, possibilitaram uma ampliação do atendimento da educação infantil, da creche à pré-escola, por parte dos municípios, efetivando o regime de colaboração entre os entes federados, previsto constitucionalmente no Art. 30.

$O$ que se pode verificar no contexto atual é que os avanços no atendimento da educação infantil foram significativos após a implantação do FUNDEB, ainda que este atendimento não esteja sendo realizado na sua totalidade, já que nem todas as crianças de 0 (zero) a 3 (três) são contempladas. Prova disso, são as filas de espera por vagas nas creches existente em quase todos os municípios brasileiros, o que impossibilita o acesso de todas as crianças nestas instituições, já que não há vagas para todas as famílias interessadas em colocar seus filhos nessa etapa da educação básica.

Se os recursos do FUNDEB, ainda que representando um avanço significativos para o atendimento da educação infantil, não foram suficientes para a universalização deste atendimento na faixa de 0 (zero) a 3 (três) anos de idade, outro problema pode surgir. Assim como o FUNDEF foi criado para durar 10 (dez) anos, o FUNDEB também foi aprovado legalmente com uma data para iniciar (2007) e para terminar. Isso irá ocorrer em 2020, prazo estipulado para o fim de vigência do FUNDEB, já que de acordo com o Art. 60, do Ato de disposições Constitucionais Transitórias, o fundo foi aprovado para durar 14 (catorze) anos.

Caso isso venha ocorrer, sem uma prorrogação ou substituição do atual fundo em vigor, a educação básica como um todo pode passar por um retrocesso no que tange o seu financiamento. Como aponta Sena, com o seu 
término legal em 2020: “[...] o Fundeb deixará de ter suporte jurídico, hipoteticamente havendo retorno à situação anterior ao Fundeb e ao próprio Fundef - deixaria de haver o mecanismo redistributivo dos fundos contábeis" (2015, p. 5). Desta maneira, o Brasil pode então regressar ao sistema de convênios, relegados às questões político-partidárias, como já ocorria anteriormente, antes da criação dos fundos de financiamento educacional (SENA, 2015).

Nesta perspectiva, os municípios brasileiros, responsáveis pela oferta da educação infantil, podem ter problemas financeiros para manutenção das suas creches, da pré-escolas e dos anos iniciais do ensino fundamental, já que economicamente recebem menos recursos de impostos, do que os estados e a União. E os mais afetados serão os municípios menores, pois são duplamente prejudicados, já que sofrem injustiças por parte da redistribuição do atual FUNDEB e suas arrecadações são bem inferiores se comparadas aos municípios maiores e desenvolvidos industrialmente.

Como proposta para tentar evitar que essa desestruturação ocorra na educação básica com o fim do FUNDEB, está tramitando na Câmara dos Deputados do Brasil uma PEC de autoria da deputada Raquel Muniz (PMDB) desde 2015. Esta PEC no 15, de 2015, tem como objeto principal transformar o atual FUNDEB de Ato das Disposições Constitucionais Transitórias (ADCT) em um fundo permanente através de sua inclusão na Constituição Federal.

Segundo Sena, a PEC no 15, de 2015, além da proposta de tornar o atual FUNDEB em um instrumento permanente de financiamento da educação básica pública, também preconiza:

[...] corrige esta lacuna, ao trazer a previsão do planejamento, também, para a ordem social. [...] contém importante avanço, ao estabelecer que o planejamento, como processo, deve prever a participação da sociedade na

formulação, acompanhamento contínuo, monitoramento e avaliação periódica das políticas sociais (2015, p. 7).

Para a educação infantil, uma das etapas da educação básica que poderia ser mais afetada pelo fim do FUNDEB, a proposta da PEC $\mathrm{n}-15$, de 2015, não apenas procura manter a garantia de recursos fixos para sua manutenção, mas busca trazer outras mudanças na lei atual. Uma dessas mudança podem afetar diretamente a educação infantil:

A PEC no 15, de 2015, propõe inserir o Art. 212-A $\mathrm{A}^{4}$ na Constituição Federal de 1988 e tem como premissa alterar o termo "educação básica", que se encontra no Art. 60, inciso III, do Ato de Disposição Constitucional Transitória, para "[...] educação básica obrigatória e gratuita dos quatro aos dezessete anos e ampliação da oferta para as crianças de até quatro anos de idade".

Assim, a educação infantil, já consolidada como modalidade da educação básica, passaria a ter mais um reforço legal para o seu atendimento financeiro, não deixando nenhuma justificativa para interpretações equivocadas de que a etapa a ser privilegiada pelo novo fundo deverá ser a faixa etária dos 4 (quatro) a 5 (cinco) anos, idade escolar obrigatória.

Desta maneira, ainda que não seja um mecanismo ideal de financiamento educacional, a manutenção do fundo contábil como financiador da educação se faz necessária. Os retrocessos que a educação básica brasileira e, principalmente, a educação infantil poderiam sofrer são incalculáveis, podendo retroceder em algumas conquistas que foram obtidas nos últimos anos. Conquistas estas que, ainda que tenham sido pequenas diante dos desafios enfrentados pela educação infantil, foram significativas para a manutenção do sistema de ensino brasileiro nas últimas duas décadas, com a criação dos fundos contábeis de financiamento educacional.

\section{CONSIDERAÇÕES FINAIS}

\footnotetext{
${ }^{4}$ Art. 3o É inserido o art. 212-A na Constituição Federal com a seguinte redação: "Art. 212-A. Os Estados, o Distrito Federal e os Municípios destinarão parte dos recursos a que se refere o caput do art. 212 da Constituição Federal à manutenção e desenvolvimento da educação básica e à remuneração condigna dos trabalhadores da educação, respeitadas as seguintes disposições: [...] III - observadas as garantias estabelecidas no $\S 1$ 10 e nos incisos I, II, III e IV do caput do art. 208 da Constituição Federal e as metas de universalização da educação básica obrigatória e gratuita dos quatro aos dezessete anos e ampliação da oferta para as crianças de até quatro anos de idade, estabelecidas no Plano Nacional de Educação (BRASIL, 2015 grifo nosso).
} 
Dentro de uma perspectiva histórica, pode-se perceber que a educação infantil no Brasil não foi uma prioridade do Estado, sendo aceita como parte da escolaridade necessária apenas a partir da Constituição Federal de 1988 e, principalmente, com a LDB 9.394/96, que instituiu a educação infantil como modalidade da educação básica.

Mesmo com essas conquistas legais, até o ano de 2007, a modalidade não recebia recursos financeiros específicos e suficientes dos estados e da União para sua manutenção, já que sua oferta ficava exclusivamente a cargo dos municípios, entes federados com menores capacidades de arrecadação. A cooperação legal entre os municípios, os estados e a União para a manutenção do sistema de ensino também não acontecia de maneira satisfatória.

Com a criação do FUNDEB, em 2006, a educação infantil passou a ser atendia por esse fundo contábil de financiamento da educação. Assim, essa modalidade começou a receber recursos dos respectivos estados e da União, que complementavam as verbas do fundo, propiciando certos avanços no atendimento da modalidade pelos municípios, principalmente os de maior população e melhor desenvolvimento econômico.

Mas, mesmo com esses recursos do fundo, verifica-se que o FUNDEB não conseguiu romper com as desigualdades no atendimento das crianças nos municípios mais pobres e com menor capacidade de arrecadação. No entanto, seria errôneo dizer que o FUNDEB não tenha possibilitado uma ampliação no atendimento das crianças, no Brasil, após a sua implantação. Ainda que não seja considerado um instrumento ideal para o financiamento educacional, o fundo possibilitou um fluxo financeiro fixo e contínuo anualmente aos municípios, o que por si só representou uma grande conquista para os municípios responsáveis por manter a educação infantil.

Com o seu fim, em 2020, as melhorias proporcionadas ao atendimento da criança nas creches e pré-escolas podem ser prejudicadas. Para isso, a proposta da PEC no 15 , de 2015, é tornar o FUNDEB um fundo permanente de financiamento educacional, para evitar que ocorra um retrocesso nas conquistas proporcionadas à educação básica no Brasil, após a implantação dos fundos contábeis: FUNDEF e FUNDEB.

\section{REFERÊNCIAS}

BANCO MUNDIAL. Prioridades y estrategias para la educación: examen do Banco Mundial. Washington, DC: World Bank, 1995.

BRASIL. Constituição (1988). Constituição da República Federativa do Brasil. Brasília-DF: Senado Federal, 1988.

Estatuto da criança e do adolescente. Lei federal no 8069, de 13 de julho de 1990. Dispõe sobre o Estatuto da Criança e do Adolescente e dá outras providências. Disponível em: <http://www.planalto.gov.br/ccivil_03/LEIS/L806 9.htm>. Acesso em: 12 jun. 2017

Lei de Diretrizes e Bases da Educação Nacional. Lei no 9.394, de 20 de dezembro de 1996. Estabelece as diretrizes e bases da educação nacional. Disponível em: <http://www.planalto.gov.br/CCIVIL_03/Leis/L93 94.htm.>. Acesso em: 12 jun. 2017

Proposta de Emenda à Constituição no 15, de 2015. Da Sra. Raquel Muniz e outros. Disponível em: <http://www.camara.gov.br/proposicoesWeb/pr op_mostrarintegra?codteor $=1317615$ \&filename= PEC+15/2015>. Acesso em: 12 jun. 2017.

Lei no 12.796, de 4 de abril de 2013. Altera a Lei no 9.394, de 20 de dezembro de $1996 . \quad$ Disponível em: <http://www.planalto.gov.br/CCIVil_03/_Ato201 1-2014/2013/Lei/L12796.htm>. Acesso: 04 abr. 2018.

DAVIES Nicholas. FUNDEB: a redenção da educação básica? Educação \& Sociedade. Campinas, v. 27, n. 96 - Especial, p. 753-774, out. 2006.

DECLARAÇÃO DE JOMTIEN. In: MENEZES, Ebenezer Takuno. Dicionário Interativo da Educação Brasileira - Educabrasil. São Paulo: Midiamix, 2001. Disponível em: <http://www.educabrasil.com.br/declaracao-dejomtien/>. Acesso em: 16 out. 2017.

GASPAR, Maria de Lourdes Ribeiro. Os impactos do FUNDEB na Educação Infantil brasileira: oferta, qualidade e financiamento. Evidência, Araxá, n. 6, p. 121-136, 2010. 
KHULMANN Jr., Moysés. Infância e educação infantil - uma abordagem histórica. Porto Alegre: Mediação, 1998.

UNESCO. Declaração Mundial sobre Educação Para Todos (Conferência de Jomtien). Tailândia: Unesco, 1990.

ONU. Declaração dos direitos da criança, de 20 de novembro de 1959. Disponível em: <http://www.direitoshumanos.usp.br/index.php/ Crian\%C3\%A7a/declaracao-dos-direitos-dacrianca.html>. Acesso em: 21 set. 2017.

SENA, Paulo. A PEC no 15/2015 e o Novo Fundeb. Câmara do Deputados: Brasília-DF, 2015. Nota Pública.

Recebido para publicação em: 28/10/2017

Revisado em: 27/11/2017

Aceito em: 28/01/2018 